\title{
PERSEPSI GURU SEJARAH TERHADAP EKSISTENSI MUSEUM NEGERI NTB SEBAGAI SUMBER BELAJAR DAN MEDIA PEMBELAJARAN
}

\author{
${ }^{1}$ Nurhajjah, ${ }^{2}$ Badarudin, ${ }^{3}$ B. Fitri Rahmawati \\ ${ }^{1,2,3}$ Universitas Hamzanwadi \\ fitri.fkiphamzanwadi@gmail.com
}

\begin{abstract}
Abstrak
Tujuan penelitian ini adalah untuk mengetahui persepsi guru sejarah tentang eksistensi museum Negeri Nusa Tenggara Barat sebagai sumber dan media pembelajaran sejarah. Penelitian ini menggunakan penelitian kualitatif dengan metode deskriftif. Penelitian ini berfokus pada persepsi guru sejarah tentang keberadaan museum Negeri Nusa Tenggara Barat dalam pembelajaran sejarah di Madrasah Aliyah Kecamatan Aikmel. Sumber data yang digunakan adalah data primer dan data sekunder. Teknik pengumpulan data melalui observasi langsung, wawancara, dan dokumentasi. Teknik triangulasi sumber dan metode peneliti gunakan untuk menguji keabsahan data. Analisis data dapat dilakukan dengan cara interaktif dan berlangsung terus menerus sampai tuntas. Hasil dari penelitian ini adalah Eksistensi Museum Negeri NTB dapat memberikan manfaat sebagai sumber dan media dalam pembelajaran sejarah. Terdapat beragam manfaat yang diperoleh dalam pembelajaran sejarah ketika memanfaatkan museum sebagai sumber dan media pembelajaran yaitu: 1) siswa memiliki pengalaman yang konkrit dalam belajar sejarah, karena museum memiliki koleksi mengenai bukti-bukti dari peristiwa sejarah yang dipelajari. Hal ini dapat memberikan hasil belajar yang lebih bermakna; 2) guru memiliki referensi tambahan dalam membelajarkan sejarah, sehingga dapat melengkapi kekurangan sumber pembelajaran; 3) guru dapat menerapkan metode karya wisata sebagai alternatif untuk menciptakan pembelajaran yang lebih bervariasi; 4) siswa menjadi lebih termotivasi untuk belajar sejarah; 5) menghilangkan rasa bosan dalam belajar sejarah.
\end{abstract}

Kata Kunci: persepsi guru, sumber belajar, media pembelajaran

\begin{abstract}
The purpose of this research is to know the perception of history teachers about the existence of the West Nusa Tenggara State Museum as a source and as a medium of historical learning. This study uses qualitative research with descriptive methods. This study focuses on the perception of history teachers about the existence of the West Nusa Tenggara State museum in history learning in Madrasah Aliyah, Aikmel District. Data sources used are primary data and secondary data. Data collection techniques through direct observation, interviews, and documentation. Source triangulation techniques and methods researchers use to test the validity of the data. Data analysis can be done in an interactive way and continues until complete. The results of this study are the existence of the NTB State Museum can provide benefits as a source and medium in learning history. There are various benefits gained in learning history when using the museum as a source and learning medium, namely: 1) students have concrete experiences in learning history, because the museum has a collection of evidence of historical events being studied. This can provide more meaningful learning outcomes; 2) the teacher has additional references in learning history, so that it can complement the lack of learning resources; 3) teachers can apply the field trip method as an alternative to creating more varied learning; 4) students become more motivated to learn history; 5) eliminate boredom in learning history.
\end{abstract}

Keyword: teacher's perception, learning resources, learning med 
Persepsi Guru Sejarah ..... Nurhajjah, Badarudin, B. Fitri Rahmawati

\section{PENDAHULUAN}

Mata pelajaran sejarah merupakan salah satu pelajaran di Madrasah Aliyah (MA) dan memiliki arti penting dalam pembentukan kesadaran dan wawasan kebangsaan. Arti penting dalam pengembangan kesadaran dan wawasan digambarkan bahwa "tanpa mengetahui sejarahnya suatu bangsa tidak akan mengenal dan memilki identitasnya". Di samping itu kesadaran sejarah merupakan sumber inspirasi juga aspirasi. Keduanya sangat potensial untuk membangkitkan kebanggaan dan tanggung jawab dan kewajiban. Sejarah mengandung arti dalam ilmu pengetahuan yang mempelajari segala peristiwa atau kejadian yang telah terjadi pada masa lampau dalam umat manusia. Arti penting dapat juga dilihat dari segi edukatif yang bisa ditangkap dari pendidikan sejarah itu sendiri. Makna yang bisa ditangkap adalah bahwa pendidikan sejarah bisa memberikan kearifan dan kebijaksanaan bagi yang mempelajarinya. Dengan menyadari makna edukatif sejarah berarti menyadari masa lampau yang penuh arti dan selanjutnya dapat diambil dari sejarah berupa ide-ide kreatif sebagai sumber pemecahan masalah masa kini dan selanjutnya untuk merealisasikan harapan-harapan di masa yang akan datang.

Sejarah merupakan ilmu yang mempelajari tentang masa lampau. Memahami sejarah bukanlah hal yang mudah karena sudah terjadi bahkan berjuta tahun yang lalu. Kejadian masa lalu dapat diketahui dan dikonstruksi lewat bukti yang ditinggalkannya. Namun tidak sedikit dari peristiwa-peristiwa tersebut hanya meninggalkan bukti yang minim. Hal ini menyebabkan sulitnya konstruksi tentang masa lalu yang sudah terjadi.

Di tingkat sekolah, sejarah dibelajarkan menggunakan sumber-sumber berupa buku teks yang sudah jadi, yang biasanya disusun oleh pemerintah. Buku teks yang ada hanya berisi penjelasan-penjelasan masih abstrak, seperti yang dinyatakan Ahmad bahwa upaya pemahaman pelajar hanya dengan penggunaan buku teks mengalami kendala karena dalam buku teks informasi yang diberikan hanya dalam bentuk verbal yang bersifat abstrak. Oleh karena itu, guru memerlukan sumber belajar lain untuk melengkapi sumber belajar dalam pembelajaran sejarah, salah satunya adalah museum (Ahmad, 2010: 107).

Museum adalah tempat panyimpanan benda-benda bersejarah, semua benda yang ada di museum merupakan benda peninggalan sejarah yang semestinya dilestarikan, supaya bangsa Indonesia tidak lupa akan perjuangan para pejuang bangsa yang membela tanah air dan sejarah bangsa lainnya. Seperti yang dinyatakan Suraya bahwa museum merupakan tempat pelestarian, bukan hanya secara fisik, tetapi dalam sistem nilai dan norma. Tujuan pelestarian adalah agar masyarakat tidak melupakan kekayaan budaya atau tidak mengenal lagi akan kebudayaan mereka (Suraya, 2016: 2). Didirikannya museum maka bangsa 
Persepsi Guru Sejarah ..... Nurhajjah, Badarudin, B. Fitri Rahmawati

Indonesia tidak akan lupa tentang sejarah bangsanya karena bangsa juga harus mendapatkan pendidikan, agar bangsa kita tidak terjajah oleh bangsa lain. Prinsipnya pendidikan merupakan bentuk kesadaran masyarakat yang ingin meningkatkan peradabannya, sehingga mereka menguasai ilmu pengetahuan dan mempunyai jati diri, peran masyarakat dipendidikan sejak semula sudah terlihat, baik melalui lembaga-lembaga pendidikan maupun organisasiorganisasi masyarakat. Hal ini senada dengan yang dinyatakan Nugroho dan Mareza bahwa museum tidak hanya berfungsi sebagai lembaga yang mengumpulkan dan memamerkan benda-benda yang berkaitan dengan sejarah perkembangan kehidupan manusia dan lingkungan, tetapi merupakan suatu lembaga yang mempunyai tugas untuk melakukan pembinaan dan pengembangan nilai budaya bangsa guna memperkuat kepribadian dan jati diri bangsa, mempertebal keimanan dan ketakwaan kepada Tuhan, serta meningkatkan rasa harga diri dan kebanggaan nasional (Nugroho \& Mareza, 2016). Selain itu, museum sebagai bagian dari lingkungan sekitar merupakan sarana bagi siswa dimana siswa dapat beraktivitas, berekreasi, berinovasi, termasuk mengembangkan pikiran sehingga membentuk perilaku baru dalam kegiatannya. Dengan kata lain lingkungan dapat dijadikan sebagai laboratorium atau tempat bagi siswa untuk mendapatkan konsep dan informasi baru sebagai wujud dari hasil belajar siswa. Museum menurut Kartikadarma, dkk adalah merupakan suatu badan yang mempunyai tugas dan kegiatan untuk memamerkan dan menerbitkan hasil-hasil penelitian dan pengetahuan tentang benda-benda yang penting bagi Kebudayaan dan 1lmu Pengetahuan (Kartikadarma et al., 2015: 64).

Pemanfaatan museum sebagai sumber belajar dapat memberikan respon yang positif pada mata pelajaran sejarah, baik sejarah lokal, sejarah nasional dan sejarah dunia. Di antaranya yaitu pemanfaatan museum sebagai sumber belajar dalam pembelajaran sejarah (Ibrahim, 2018: 216). Pengalaman yang didapatkan siswa dari pengamatan pada objek-objek yang disimpan museum secara langsung akan dapat menunjang proses pembelajaran sejarah (Agam, 2014: 27). Pemanfaatan lingkungan seperti situs sejarah atau pun museum sebagai sumber belajar dapat dapat dilakukan melalui metode karya wisata atau metode di luar kelas. Metode ini dapat meningkatkan keaktifan siswa dalam pembelajaran sehingga pembelajaran menjadi lebih menarik dan menyenangkan. Hal ini juga dinyatakan Ventyasari bahwa metode belajar di luar kelas yang dilakukan oleh guru dapat membantu siswa dalam pembelajaran sejarah serta siswa sangat berantusias (Ventyasari, 2015: 84).

Selain sebagai sumber belajar, museum juga dapat dimanfaatkan sebagai media pembelajaran. Peran media sangat diperlukan dalam pengajaran sejarah. Hal ini selain mempermudah guru dalam penyampaian materi, media berfungsi untuk mengembangkan 
kemampuan indera peserta didik. Seperti yang dinyatakan Oktaviani bahwa museum dapat dimanfaatkan sebagai media pembelajaran melalui museum masuk sekolah (Oktaviani, 2016: 11). Koleksi-koleksi yang ada di museum menjadi bantuan yang berharga bagi guru dalam memberikan kehidupan dan realitas pembelajaran di sekolah, di semua tingkat dalam pendidikan formal. Dan museum termasuk kedalam media by utilization. Dalam museum, karakteristik media yang lazim ditemukan adalah (1) media pandang (visual), baik yang diproyeksikan atau tidak, dan (2) sistem multimedia seperti media elektronik dalam bentuk audio visual. Seperti yang dinyatakan Hartati bahwa museum dapat digunakan sebagai media pembelajaran dengan menyesuaikan materi pelajaran (Hartati, 2016: 2). Penggunaan museum sebagai media pembelajaran disebabkan karena kompleksitas media yang tersedia sebagai penjelasan suatu peristiwa. Di NTB terdapat salah satu museum yakni Museum Negeri NTB. Pentingnya pemanfaatan museum dalam pembelajaran sejarah mendasari peneliti untuk melakukan kajian tentang persepsi guru sejarah terhadap eksistensi Museum Negeri NTB sebagai sumber dan media pembelajaran sejarah.

\section{METODE PENELITIAN}

Penelitian ini menggunakan pendekatan kualitatif dengan metode deskriptif. Dalam penelitian kualitatif menurut Sugiyono, terdapat tiga tahap yakni tahap deskripsi ketika peneliti memasuki konteks penelitian, tahap kedua adalah peneliti menentukan fokus penelitian dan tahap ketiga yakni peneliti mengurai fokus menjadi komponen yang lebih rinci (Sugiyono, 2010: 17). Penelitian ini dilakukan di MA Kecamatan Aikmel, Lombok Timur. Data dalam penelitian ini terdiri atas data primer dan data sekunder. Data primer adalah data yang diperoleh secara langsung melalui pengamatan dan wawancara dengan informan atau responden. Informan dalam penelitian ini adalah pengelola museum dan guru sejarah di MA Kecamatan Aikmel sebanyak 11 orang yang disajikan dalam table berikut dengan menggunakan inisial:

Tabel 1. Daftar Informan

\begin{tabular}{ccc}
\hline No & Inisial Informan & Jenis Kelamin \\
\hline B & Laki-laki \\
ZT & Laki-laki \\
MR & Laki-laki \\
H & Perempuan \\
MH & Laki-laki \\
MAS & Laki-laki \\
HB & Perempuan \\
AI & Laki-laki \\
T & Perempuan \\
\hline
\end{tabular}




\begin{tabular}{cc}
\hline $\mathrm{S}$ & Laki-laki \\
$\mathrm{M}$ & Perempuan \\
\hline
\end{tabular}

Sedangkan data sekunder merupakan data tambahan berupa informasi yang akan melengkapi data primer. Data tambahan yang dimaksud meliputi dokumen atau arsip yang didapatkan dari berbagai sumber, foto pendukung yang sudah ada, maupun foto yang dihasilkan sendiri, serta data yang terkait dalam penelitian ini. Data tambahan dalam penelitian ini adalah arsip data atau dokumentasi dari situs museum Negeri NTB. Penentuan informan penelitian menggunakan dua teknik yaitu purpusive sampling dan snowball sampling. Teknik pengumpulan data dilakukan dengan wawancara, observasi dan dokumentasi. Adapun teknik yang digunakan untuk keabsahan data adalah triangulasi yaitu pengecekan data dari berbagai sumber dan berbagai cara. Sedangkan teknik analisis data yang digunakan adalah teknik Miles dan Huberman (Sugiyono, 2010: 91), yang terdiri atas reduksi data, penyajian data, dan penarikan kesimpulan atau verifikasi.

\section{HASIL DAN PEMBAHASAN}

Museum merupakan sebuah lembaga yang bersifat tetap, tidak mencari keuntungan, melayani masyarakat dan perkembangannya terbuka untuk umum yang bertugas merawat, mengumpulkan, melestarikan, meneliti,dan memamerkan warisan sejarah kemanusiaan yang berwujud benda yang bertujuan untuk pendidikan, penelitian, dan hiburan. Museum merupakan salah satu tempat yang pernah dikunjungi oleh setiap lapisan masyarakat seperti halnya pengunjung yang datang ke Museum Negeri NTB. Menurut salah seorang pengelola museum Negeri NTB, bahwa ada tiga tujuan utama pengunjung ke museum NTB yaitu penelitian, pendidikan dan rekreasi. Oleh karena itu, sangat tepat jika museum dijadikan sebagai sumber belajar sejarah. Museum termasuk dalam sumber belajar yang sudah tersedia (learning resources by utilization) yaitu sumber belajar yang telah ada untuk maksud nonintruksional, tetapi dapat dimanfaatkan sebagai sumber belajar yang kualitasnya setingkat dengan sumber belajar jenis by design. Contohnya: safari garden, kebun raya, taman nasional, museum, kebun binatang, dan sebagainya.

Berkaitan dengan keberadaan museum Negeri NTB, semua guru sejarah menyatakan senang karena keberadaannya dapat membantu menyediakan sumber belajar dan media pembelajaran khususnya dalam pembelajaran sejarah. Sebagai sumber belajar, Museum NTB dapat memberikan bukti mengenai peristiwa sejarah yang terjadi pada masa lampau. Seperti yang dinyatakan oleh salah seorang guru bahwa Museum Negeri NTB sebagai sumber belajar 
Persepsi Guru Sejarah ..... Nurhajjah, Badarudin, B. Fitri Rahmawati

sangat memberikan manfaat bagi siswa maupun guru karena dapat memberikan pengalaman yang kongkrit kepada siswa dan dapat memberikan referensi bagi guru sejarah. Guru lainnya menyatakan bahwa museum Negeri NTB sebagai sumber belajar sangat memberi manfaat bagi guru maupun siswa yaitu mempermudah guru (khususnya guru sejarah) dalam proses pembelajaran sejarah dan begitu juga kepada siswa, siswa dapat belajar secara langsung dengan melihat dan mengamati benda-benda sejarah yang ada di museum yang dengan hal itu siswa akan lebih cepat paham. Selain manfaat tersebut, manfaat lainnya dari museum sebagai sumber belajar adalah dapat memberikan contoh nyata kepada siswa terkait dengan materi yang dipelajari di dalam buku yang sifatnya masih abstrak. Menurut salah satu pengelola museum, cara memanfaatkan Museum Negeri NTB sebagai sumber belajar yaitu dengan pendampingan. Pengunjung yang datang didampingi untuk memudahkan mereka mengetahui jenis koleksi yang ada di Museum, sehingga nantinya dapat menambah wawasan mengenai benda yang mereka lihat sendiri. Kemudian pengunjung diajak untuk merefleksikan dan memperdalam apa yang sudah mereka lihat. Dengan kegiatan ini, para pengunjung diharapkan dapat lebih mencintai warisan budaya yang dimiliki bangsa Indonesia. Kegiatan yang dilakukan di museum pun beragam, ketika para pengunjung (guru dan siswa) datang ke museum Negeri NTB kegiatan yang sering dilakukan sebagian besar mengamati, melihat dan mecari tahu nilai sejarah dari masing-masing benda koleksi yang di museum. Keberadaan museum Negeri NTB juga dapat memberikan keefektifan dan efisiensi dalam penggunaan sumber belajar. Dengan adanya museum yang berlokasi di Mataram ini, guru dan siswa tidak perlu lagi ke luar daerah untuk melihat secara langsung bukti-bukti peninggalan sejarah.

Menurut ICOM (Internasional Council of Museum), fungsi museum di antaranya pengumpulan dan pengamanan warisan alam dan budaya, dokumentasi dan penelitian ilmiah, pengenalan dan penghayatan kesenian, pengenalan kebudayaan antar-daerah dan antarbangsa, visualisasi warisan alam dan budaya, cermin pertumbuhan peradaban umat manusia, dan pembangkit rasa bertakwa dan bersyukur kepada Tuhan Yang Maha Esa. Dari fungsi tersebut, Museum ingin menumbuhkan kesan kagum kepada setiap pengunjung yang datang ke museum.caranya dengan menampilkan koleksi-koleksi yang dapat memberi pengaruh bagi pengunjung yang datang. Melalui koleksi tersebut, nantinya akan menimbulkan sikap cinta tanah air yaitu dengan menjaga warisan budaya yang dimiliki bangsa Indonesia.

Sebagai media pembelajaran, museum merupakan tempat ideal sebagai sumber informasi kesejarahan. Hal ini dikarenakan dalam museum terdapat banyak benda yang dapat dijadikan sebagai media pembelajaran yang berfungsi sebagai sarana peningkatan pemahaman terhadap peristiwa sejarah bagi siswa.Museum dapat digunakan sebagai alat penunjang 
pelajaran khususnya sejarah dan sebagai peraga budaya masa lampau, koleksi yang ada di museum merupakan sumber belajar yang kongkret bagi siswa dalam pembelajaran sejarah.

Koleksi museum yang dapat digunakan sebagai media belajar sejarah adalah koleksi yang bersifat visual dan tidak membosankan seperti fosil binatang purba (misalnya buaya purba), dan hasil budaya manusia purba (misalnya kapak genggam). Untuk meningkatkan pemahaman mengenai kehidupan manusia zaman prasejarah, guru tidak perlu lagi menggunakan media gambar karena di dalam museum terdapat miniatur buaya purbayang dapat memperkuat pemahaman mengenai masa pra aksara. Melalui panca indera, utamanya pada indera penglihatan (mata), pada miniatur buaya purba dapat dipahami lebih cepat dibandingkan hanya ketika guru menjelaskan secara konvensional (ceramah) dan peserta didik memberikan apresiasi melalui pembelajaran yang menggunakan media museum dan rasa senang, karena dapat menganalisis menurut pendapatnya sendiri. Adapun kapak genggam (Chopper), dapat dimanfaatkan untuk menjelaskan hasil kebudayaan manusia purba yang digunakan untuk berburu binatang seperti rusa, kerbau, gajah, dan lain sebagainya.

Menurut pendapat salah seorang guru sejarah yang menyatakan bahwa museum sangat cocok dijadikan sebagai media pembelajaran sejarah karena siswa akan mendapatkan pengetahuan yang kongkret dan siswa juga akan merasa senang dan termotivasi. Pengguna museum sebagai sumber belajar merupakan salah salah satu cara efektif dalam mewujudkan tujuan pembelajaran sejarah. Hal ini dikarenakan di dalam museum terdapat berbagai macam media yang memberikan informasi konkret kepada siswa tentang peristiwa masa lampau. Museum dapat memberikan pengalaman yang lebih nyata dalam pembelajaran sejarah bagi siswa dari pembelajaran yang menggunakan buku teks. Dengan demikian museum sebagai media pembelajaran sejarah berfungsi untuk mewujudkan visualisasi, interpretasi dan generalisasi siswa. Melaui pemanfaatan peninggalan-peninggalan sejarah yang terdapat di museum tersebut maka akan berpengaruh terhadap pencapaian hasil belajar siswa.

Museum Negeri NTB menyimpan koleksi-koleksi peninggalan sejarah yang dapat dijadikan sebagai sumber belajar dan media pembelajaran yang konkret bagi siswa. Dimana koleksi museum Negeri NTB sebanyak 7698 dan dibagi menjadi 10 jenis diantaranya yaitu sebagai berikut: 1) Geologika, yaitu koleksi-koleksi benda alam. Seperti bebatuan, fosil dari kayu; 2) Biologika, yaitu koleksi flora dan fauna. Koleksi faunanya seperti ada buaya, kurakura dan rusa yang sudah diawetkan. Dan floranya kebanyakan dari kayu-kayu asli Nusa Tenggara Barat seperti garut; 3) Eknografika, yaitu koleksi benda budaya yang mencirikan suatu etnis yaitu pakaian adat, alat berburu dan menangkap ikan dari masing-masing daerah; 4) Arkeologika, yaitu koleksi benda temuan/benda-benda masa lalu yang diperoleh dari hasil 
temuan, baik temuan dari bawah tanah atau temuan bawah laut misalnya ada temuan gunung piring di Lombok Tengah, dan ada juga patung Siwa Maha Dewa di Pringgabaya. Dan ada juga penemuan pada masa prasejarah seperti pada masa mesolitikum paleolitikum neolitikum ada di museum Negeri NTB; 5) Historika, yaitu koleksi benda sejarah tetapi bukan hasil temuan seperti warisan pakaian datu Pejanggi atau datu Selaparang itu dibuat dari warisan orang tua pada zaman dahulu; 6) Numismatika, yaitu koleksi mata uang seperti uang bolong atau uang-uang kuno; 7) Heraldik yaitu setiap tanda jasa, lambing dan tanda pangkat resmi; 8) Filologika yaitu koleksi naskah kuno seperti tulisan huruf Jawa hanacaraka; 9) Kramologika yaitu keramik asing seperti keramik dari Cina, Eropa dan Asia tenggara; dan 10) kesenian yaitu koleksi alat musik, topeng, dan wayang. Pengelompokan benda ke dalam sepuluh jenis tersebut bertujuan untuk memudahkan dalam pengelolaan serta memudahkan para pengunjung untuk memahami peninggalan-peninggalan sejarah di museum Negeri NTB. Koleksi benda-benda di museum ini dapat dimanfaatkan sebagai sumber dan media pembelajaran sejarah mulai dari materi praaksara, Hindu-Budha, Islam dan Sejarah Lokal.

Pemanfaatan museum Negeri NTB sebagai sumber dan media pembelajaran memberikan pengaruh yang cukup besar dalam pembelajaran sejarah. Seperti yang diungkapkan salah seorang guru bahwa dengan adanya museum sebagai sumber belajar sejarah dapat memudahkan siswa dalam menangkap langsung pengetahuan yang didapat melalui pengamatan benda-benda sejarah. Guru lainnya menyatakan bahwa keberadaan museum sebagai sumber dan media pembelajaran memberikan pengalaman langsung kepada siswa sehingga hasil belajar menjadi lebih bermakna. Selain itu juga dapat mengurangi rasa bosan saat belajar.

Pembelajaran sejarah sering digambarkan sebagai pembelajaran yang membosankan. Penggunaan metode yang kurang variatif disinyalir menjadi salah satu penyebabnya. Oleh karena itu, keberadaan museum sebagai sumber dan media pembelajaran dapat dimanfaatkan guru untuk menciptakan variasi dalam pembelajaran. Salah satu metode yang dapat diterapkan guru adalah metode karya wisata. Dengan pembelajaran di luar kelas siswa akan membentuk pengetahuan pada dirinya dari setiap benda yang diamati, seperti gambar, foto, sketsa, atau grafik yang nantinya akan menumbuhkan sikap kritis dalam menanggapi setiap hal yang disampaikan baik di kelas maupun di luarkelas. Pengalaman yang diperoleh siswa melalui karyawisata ini sangat berarti, dalam hal memperkaya dan memperluas pengalaman belajar siswa. Dengan demikian pembelajaran menjadi tidak membosankan. Dwiyantoro, Lestari dan Mursidi juga menyatakan bahwa pemanfaatan museun sebagai sumber belajar adalah dengan menerapkan metode karya wisata dan penugasan kepada siswa (Dwiyantoro, 
Persepsi Guru Sejarah ..... Nurhajjah, Badarudin, B. Fitri Rahmawati

2012; Lestari, 2012; Mursidi, 2010: 98).

\section{KESIMPULAN}

Eksistensi Museum Negeri NTB dapat memberikan manfaat sebagai sumber dan media dalam pembelajaran sejarah. Terdapat beragam manfaat yang diperoleh dalam pembelajaran sejarah ketika memanfaatkan museum sebagai sumber dan media pembelajaran yaitu: 1) siswa memiliki pengalaman yang konkrit dalam belajar sejarah, karena museum memiliki koleksi mengenai bukti-bukti dari peristiwa sejarah yang dipelajari. Hal ini dapat memberikan hasil belajar yang lebih bermakna; 2) guru memiliki referensi tambahan dalam membelajarkan sejarah, sehingga dapat melengkapi kekurangan sumber pembelajaran; 3) guru dapat menerapkan metode karya wisata sebagai alternatif untuk menciptakan pembelajaran yang lebih bervariasi; 4) siswa menjadi lebih termotivasi untuk belajar sejarah; 5) menghilangkan rasa bosan dalam belajar sejarah.

\section{DAFTAR PUSTAKA}

Agam, D. T. (2014). Studi Komparasi Pemanfaatan Museum Kartini sebagai Sumber Belajar. Indonesian Journal of History Education, 3(1).

Ahmad, T. A. (2010). Strategi pemanfaatan museum sebagai media pembelajaran pada materi zaman prasejarah. Paramita: Historical Studies Journal, $20(1), 107$.

Dwiyantoro, S. (2012). Museum Sangiran (Historisitas dan Relevansinya Sebagai Sumber Pembelajaran Sejarah).

Hartati, U. (2016). Museum Lampung sebagai Media Pembelajaran Sejarah. Historia: Jurnal Program Studi Pendidikan Sejarah, 4(1), 1-10.

Ibrahim, N. (2018). Pemanfaatan Museum sebagai Sumber Belajar dalam Pembelajaran Sejarah. Visipena Journal, 9(2), 215-235.

Kartikadarma, E., Rizqa, I., \& Trirosandi, D. (2015). Rancang Bangun Aplikasi E-museum sebagai Upaya Melestarikan Kebudayaan. Seminar Nasional Informatika (SEMNASIF), 1(5).

Lestari, J. (2012). Fungsi Museum Blambangan Kabupaten Banyuwangi Sebagai Sumber Pembelajaran Sejarah.

Mursidi, A. (2010). Pemanfaatan museum blambangan Sebagai sumber belajar sejarah.

Nugroho, A., \& Mareza, L. (2016). Pemanfaatan Museum BRI dan Museum Jenderal Sudirman sebagai Sumber Belajar IPS oleh Siswa dan Guru SD di Purwokerto. Khazanah Pendidikan, 9(2). 
Persepsi Guru Sejarah ..... Nurhajjah, Badarudin, B. Fitri Rahmawati

Oktaviani, A. (2016). Peranan Museum Soeharto sebagai media pembelajaran sejarah. Prodi. Pendidikan Sejarah, FKIP, Universitas PGRI Yogyakarta.

Sugiyono, S. (2010). Memahami Penelitian Kualitatif. Bandung: Alfabeta

Suraya, M. S. (2016). E-Museum Sebagai Media Memperkenalkan Cagar Budaya Di Kalangan Masyarakat. Diambil Dari: Http://Www. Researchgate. Net/Publicatio, 280493363_Emuseum_Sebagai_Media_Me.

Ventyasari, R. (2015). Pemanfaatan Museum Trinil Sebagai Sumber Belajar Sejarah Bagi Siswa SMA Di Kabupaten Madiun Provinsi Jawa Timur Tahun Ajaran 2014/2015. Universitas Negeri Semarang. 